\title{
The Need for Homelessness Prevention: A Doctor's View of Life and Death on the Streets
}

\author{
James J. O’Connell
}

Published online: 23 June 2007

(C) Springer Science+Business Media, LLC 2007

Keywords Homelessness prevention - Medical · Health care

This issue of The Journal of Primary Prevention sounds an urgent and compelling clarion call to policy makers, politicians, advocates, clinicians, and to all committed to ending the social tragedy of homelessness in modern America.

Over the past three decades, homelessness has emerged as a complex social phenomenon that thwarts simple definitions and is perhaps best viewed as a prism that refracts the failures of key sectors of our society, including housing, welfare, labor, education, health care, and corrections. Efforts to prevent homelessness have failed in the face of the compelling urgency of the daily crisis posed by thousands of individuals and families already on our streets and in our shelters. The papers in this timely edition of JPP begin the arduous task of stemming the relentless tide of Americans swept from housing and institutions into homelessness each year. Prevention remains poorly understood and yet is the sine qua non for ending homelessness.

Homelessness in urban and rural America includes an eclectic population spanning a continuum from families with children, to adolescents and youths, to

As the founding physician and President of the Boston Health Care for the Homeless Program, Dr. O'Connell has provided medical care to homeless individuals since 1985 . The program serves over 9,000 homeless persons each year in three hospital-based clinics and over 70 shelters and other outreach sites in Boston. Dr. O'Connell founded a 90-bed freestanding medical respite program for homeless men and women and designed the nation's first computerized medical record for homeless program. His articles have appeared in the New England Journal of Medicine, the Journal of the American Medical Association, the Journal of Clinical Ethics, and several other medical journals. His work has been featured on ABC's Nightline, and he has received numerous awards during his career, including the Richard and Hinda Rosenthal Foundation Award from the American College of Physicians.

J. J. O’Connell ( $\square)$

Boston Health Care for the Homeless Program, Department of Medicine, Massachusetts General Hospital and Boston Medical Center, 729 Massachusetts Avenue, Boston, MA 02118, USA

e-mail: JOConnell@bhchp.org 
middle-aged men and women, and to the frail elderly. Numbered among the homeless are veterans, victims of domestic violence, young workers earning the minimum wage who cannot afford housing or health insurance, seasoned workers whose factories and jobs have been closed or downsized or outsourced, retired individuals with fixed incomes and rising property taxes, undocumented and migrant workers, and those struggling with debilitating medical problems, severe and persistent mental illness, and substance abuse. Persons can be homeless for a single episode, suffer through repeated episodes, or may be chronically homeless. To date, prevention strategies have been overwhelmed by the bewildering dimension and complexity of homelessness in America.

Let me share some experiences far downstream based on my work as a doctor on a team dedicated to the care of people living on the streets of Boston. On the last Friday of 2006, we ended our day with a visit to a beloved and irascible patient. He lay sedated and unresponsive in his ICU bed at Boston Medical Center, his 61-yearold body heaving with each agonal breath while the rattle of death was audible in his chest. His brother, a Navy veteran living in a nearby shelter, stood beside him. Pulmonary fibrosis had inexorably stiffened his lungs into cardboard, and now pneumonia was mercifully ending long months of his Herculean struggle for each precious breath.

This artist and fine woodworker had endured innumerable hospitalizations over the past year, punctuated by frequent admissions to McInnis House, our respite care program that offers medical and nursing care for persons with acute and chronic illnesses who have no homes in which to heal. On several occasions he absconded to the streets to taste the freedom he dearly cherished, but we would find him in Cleveland Circle near the reservoir and he would forlornly return. He read a book each day in the hospital, cherished every visit from our team, and even began to talk about a life he had always shrouded in mystery.

He had attended Boston Latin School, excelled in art and painting, had a scholarship to the museum art school, and then fell "madly and stupidly" in love with the muse of life in the 1960s. He moaned about years lost in Sing Sing because of "some foolishness over a woman." We shared stories about our mutual passion for Hawaii, where he had worked as a carpenter and where I taught high school long before entering medical school. He had started a new life there after prison, changed his name, joined the union, married, and had a child. A relentless cascade of devastating losses ultimately drove him out of paradise and home to Boston. He lost hope somewhere along his journey through the depths of depression and alcoholism.

As his doctor for over 20 years, I witnessed the courage of a man struggling against impossible odds and diminishing options. Pursued by the Furies of his past failures and bad luck, his tragedy unfolded on a public stage against the backdrop of a rich and vibrant city and before an audience calloused by stepping over him each day. I have long been drawn to the stories of these intrepid "rough sleepers," the resolute individuals who embrace rugged American individualism, adamantly eschewing the rules and crowds of shelters, and eking out a meager subsistence while living under bridges, in abandoned cars, on park benches, down back alleys, and along our downtown sidewalks and doorways. Feisty and complex, stubborn and uncompromising, these people risk the extremes of weather and temperature on 
the streets while alternately endearing and angering us. Despite the ubiquitous public presence, their lives and stories are paradoxically hidden and obscure. These urban nomads are akin to modern prophets, wandering the fringes of our cities and emerging to rant, regale, and cast doom upon a world gone astray. Their street names are revealing: Ezekiel, Isaiah, Jeremiah, Zion.

Despite high visibility and considerable publicity in the press, virtually nothing is known about the street folks who inhabit the interstices of our inner cities. Seven years ago, our team at the Boston Health Care for the Homeless Program (BHCHP) decided to prospectively follow a cohort of Boston's street population. We identified 119 individuals in January 2000, about half of Boston's year-round street folks at that time. We have continued to care for them throughout the past 7 years, and we have only lost five to follow-up. This cohort includes those who had been homeless for many years and suffered from co-occurring medical, mental health, and substance abuse issues. The demographics mirror the population of Boston, the median age at enrollment was in the mid-40s, and over $80 \%$ had medical insurance through Medicaid, Medicare, or MassHealth. Insurance and access to health care services should therefore not be an issue; rather our current mainstream health institutions and human service agencies have dramatic limitations in addressing the special needs of this vulnerable group. These persons come to our clinics in droves, but we are paralyzed by the paucity of options and choices available for men, women, and children who have no housing. The disparities in health care outcomes for homeless persons are profound and humiliating to all of us who provide care for this population. Mortality rates for chronically homeless persons in cities throughout the world are four times higher than housed persons of the same age.

Our patient died peacefully later that evening and became the 44th death among the 119 street folks (37\%) during 7 years, an astonishing mortality rate that rivals many cancers and chronic diseases. He had a chronic and progressive medical illness, but his struggle on the streets limited our treatment options and hastened his death as he suffered through repeated episodes of pneumonia and exposure. In Boston, the most common causes of death among the homeless street population have been medical and often entirely preventable: cancer, cirrhosis, HIV/AIDS, and emphysema. The Massachusetts Department of Medical Assistance found an aggregate of 18,384 emergency department visits by this cohort of 119 persons during the 5-year period from 1999 through 2003. We are still investigating the number and charges for hospital admissions, mental health and substance abuse care, ambulance and emergency medical services, and police and corrections utilization.

Health care for these chronically homeless street folks is a challenge, despite the irony that many of these individuals live in the long shadows cast by the glistening towers of our extraordinary academic medical centers. We have tried to meet the special needs of this very vulnerable group by sending our multidisciplinary medical and mental health team to comb the streets each day, work on an outreach van during the nights, and seize every opportunity for coffee or lunch to engage people in familiar and unthreatening places. Our model of care is predicated upon engagement and the formation of an enduring relationship between clinician and patient, reminiscent of the country doctor who was familiar with the unique 
situation of each patient and offered care from birth to death in the home as well as in the hospital. We provide primary and even specialty care directly on the streets, in our shelter and hospital clinics, and then assure continuity and consistency by following our patients during hospital admissions, through respite care, and into housing. We keep ourselves available by phone or beeper at all times for our patients on the streets, and have taken great pride in working within the mainstream of Boston's health care system to reach out to engage these individuals.

The devastating mortality rate of these rough sleepers is a resounding indictment of our current medical, mental health, and substance abuse systems. These impoverished individuals died at alarming rates despite our efforts to create a dynamic model that integrated continuous and high quality primary and preventive care on the streets within the mainstream of our teaching hospitals and community health centers. This group virtually lived in our emergency departments and our team of internists, psychiatrists, physician assistants, social workers, and nurses pursued them day and night across the city. Yet we were utterly unable to find ways to prevent their untimely and tragic deaths.

The painfully obvious lesson for me has been the futility of solving this complex social problem solely with new approaches to medical or mental health care. After two decades of doctoring to the homeless poor, I believe that I could best improve the health of my patients by assuring access to housing and supportive services as core components of their treatment plans. In addition to prescribing an antibiotic or insulin or a blood pressure medication, I dream of writing a prescription for an apartment, a studio, an SRO (single room occupancy), or any safe housing program, good for 1 month, with 12 refills.

Caring for homeless people poses an uneasy ethical dilemma for each health care worker. In striving to prevent illness, alleviate symptoms, and minimize suffering, our helplessness in eradicating the underlying disease process inevitably haunts and outrages us. Since the early 1980s, the response to burgeoning homelessness among individuals and families across urban and rural America has been a patchwork of programs and policies designed to shelter, treat, manage, educate, and train those who struggle without homes. This has been life-saving for many and this safety net for those living in abject poverty and homelessness must be preserved. But as we all have learned from experiences across the country, this strategy is not enough to solve the problem of homelessness. Women and men without homes bear an unacceptable burden of illness and are dying prematurely in our streets. This public health crisis will be not be ameliorated until housing, health care, and other supports become fundamental rights for every human being.

Prevention is bewilderingly complex and must be seen as part of an intricate community mosaic of housing, income, education, jobs, crime and violence prevention, race, and politics. The creation of affordable housing is necessary but by no means sufficient; health and other supportive services are critical. The societal causes of persistent poverty must be addressed, including poor schools, blighted neighborhoods, troubled foster care systems, overcrowded prisons, disappearing jobs, an escalating gap between the minimum and the living wage, and an ominous widening of the income chasm between the rich and poor. 
The prevention of homelessness is a moral imperative in any just and equitable society. The papers presented in this issue hint that primary and secondary prevention of homelessness also makes sound economic policy. The aggregate cost for shelter, food, utilization of emergency department and hospitals, police and emergency medical services, and other social services for each homeless person is significant. The working hypothesis, central to the theme of prevention, is that housing improves health and overall well-being and diminishes the utilization of many expensive health and human services. Such savings are likely to exceed the cost of the housing and thereby create a societal will for better prevention strategies.

Unfortunately, the prevention of homelessness remains an embryonic science. Most of us toil far downstream from the root causes of homelessness, responding daily to the overwhelming needs of families and individuals already on our streets and in our shelters. We have been deluged with evidence of our failures over these past three decades despite furious and creative attempts to change our health and human services models and systems. The gnawing reality is that fundamental change will only happen when housing, health, education, welfare, corrections, and other sectors in our society respond to this overwhelming public health emergency and work together to prevent and end homelessness.

Now The Journal of Primary Prevention calls us to begin this journey in earnest. Prevention will accomplish our collective goal of ending homelessness and avoiding needless deaths of individuals enduring abject poverty and struggling against impossible odds to survive without a place to call home. 